\section{On Rudolf Schwarz's The Church Incarnate: The Sacred Function of Christian Architecture}

This book was published in 1923 by Schwarz, a German architect of churches - notably St. Michael, Frankfurt - and of postwar reconstruction efforts. ${ }^{1}$ I was first introduced to it many years ago by one of my architecture school mentors. His interest was not so much in Schwarz's extensive and elaborately poetic Christian theory as in his conceptions of space and spatial sequence, visualized in evocative diagrammatic line illustrations.

Having rediscovered this book after producing the foregoing effort, I was struck by the similarities of many of its "centering modes" to his own theoretical constructs of seven "plans:" spatial archetypes for collective worship. It seemed of interest, with apologies for otherwise omitting his arguments that would be impossible to concisely summarize, to present the somewhat self-descriptive titles of these plans and adapted versions of his pertinent diagrams employing this book's vocabulary of centering ideograms. Hopefully they embody his essential graphic intentions. While grounded in issues of Roman Catholic theology, the diagrams - clearly requiring having the book in hand to discern more than a rudimentary measure of their meaning — would seem, though Schwarz might disagree, an illuminating and thought-provoking set of centering approaches for assembly partis generally.

1. The 1958 edition in English by Henry Regnery Company, Chicago, was reprinted by Nabu Public Domain Reprints.

\section{The First Plan Sacred Inwardness: The Ring}

Full Shell Array w/ Core

The Second Plan Sacred Parting: The Open Ring

Partial Full Shell Array; Radial; Partial Radial Array; w/ Core

\section{The Third Plan \\ Sacred Parting: \\ The Chalice of Light}

Partial Full Shell Array; Partial Single Shell; Radial; Dual Core

The Fourth Plan Sacred Journey: The Way

Parallel Radials; Parallel

Shells; w/out Core

\section{The Fifth Plan}

Sacred Cast: The Dark Chalice

Partial Shell; Radial w/ Core; Parallel Shell w/out Core

The Sixth Plan Sacred Universe: The Dome of Light

Full Radial Array w/ Core

The Seventh Plan The Cathedral of All Times: The Whole

Full Radial Array; Partial Shell; Radial; Parallel Shells; Dual Core

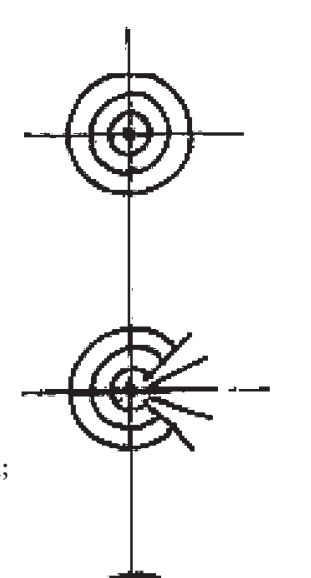

